\title{
Environmental monitoring odds by carbon nanotubes
}

\author{
Marwan S. Mousa ${ }^{1}$, Ildiko Tulbure ${ }^{2,3,4^{*}}$, and Saleh Fawaeer ${ }^{5}$ \\ ${ }^{1}$ Mu'tah University, Department of Physics, Al-Karak, Jordan \\ ${ }^{2}$ University "1 Decembrie 1918" din Alba Iulia, Romania \\ ${ }^{3}$ Technical University of Cluj-Napoca, Doctoral School "Materials and Environmental Engineering", \\ Romania \\ ${ }^{4}$ Clausthal University of Technology, Clausthal-Zellerfeld, Germany \\ ${ }^{5}$ University of Jordan, Amman, Jordan
}

\begin{abstract}
After the Conference for Environment in Stockholm 1972 and the first report to the Club of Rome „Limits of the Growth“, which has been published in same year, was finally understood, that the technological progress can bring also undesired effects. As a consequence of the recognized situation, debates on a global level have started concerning potential solutions. After long debates on scientific as well as on sociopolitical levels, the concept of Sustainable Development has been defined in the Brundtland Report of the World Commission on Environment and Development, as a potential answer. Many actions after this time emphasize that the evolution of technical, economic, as well as environmental and social systems has to be approached by considering physical, chemical, biological, economic and social processes. Registered advances in technological field combined with the field of physics, as representing basics for developments and advances in nanotechnology have emphasized the existence of its multiple using odds also in environmental field. In particular, the application of carbon nanotubes, CNTs for environmental protection seems to bring advance in this field. A first step is represented by designing environmental sensors by using CNTs in order to carry out suitable environmental monitoring for environmental protection.
\end{abstract}

\section{Sustainability Approach}

The perception beginning of undesired impacts of economic activities, especially industrial ones can be marked starting with the seventies. Since then several events have taken place on global as well as on national or regional level in order to emphasize the complexity of existing challenges and to try finding proper ways to overcome created provocations. The Conference for Environment, which took place 1972 in Stockholm and the first report to the Club of Rome „Limits to Growth“, published in same year [1] have started debates concerning resulted provoking situation, that besides desired impacts of technological

* Corresponding author: ildiko.tulbure@uab.ro 
advance, undesired effects can turn up. Nowadays we confront us with several global challenges, which can be grouped in three classes: growth of world population, increase of energy and natural resources consumption as well as environmental pollution, as presented in Figure 1. Debates, carried out on scientific, political and social levels have had as a foremost goal establishing solutions for the problems shown above, which could be applicable to developed as well as to developing countries with respect to regional differences [2].

The Brundtland Report of the World Council on Environment and Development, released 1987, represented a result of these worldwide debates for finding proper ways, defining for the first time the concept of sustainable development [3]. Several debates took place after the time of its definition, nevertheless this concept was worldwide accepted as representing a potential solution for the complex environmental, technological, economic and social challenges on global level. This concept was discussed a lot 1992 during the Conference for Environment and Development in Rio de Janeiro, having had the „Agenda $21^{\text {“ }}$ as the most important result of this conference. Ten years later took place 2002 in Johannesburg the follow-up conference called as „Rio $+10^{\prime-~ C o n f e r e n c e ~ a s ~ w e l l ~ a s ~ i n ~}$ 2012, this means 20 years after the first „Rio“ - Conference took place the new so-called „Earth Conference“ for Sustainable Development, known as „Rio + 20 - Conference“, this time again in Rio de Janeiro [4].

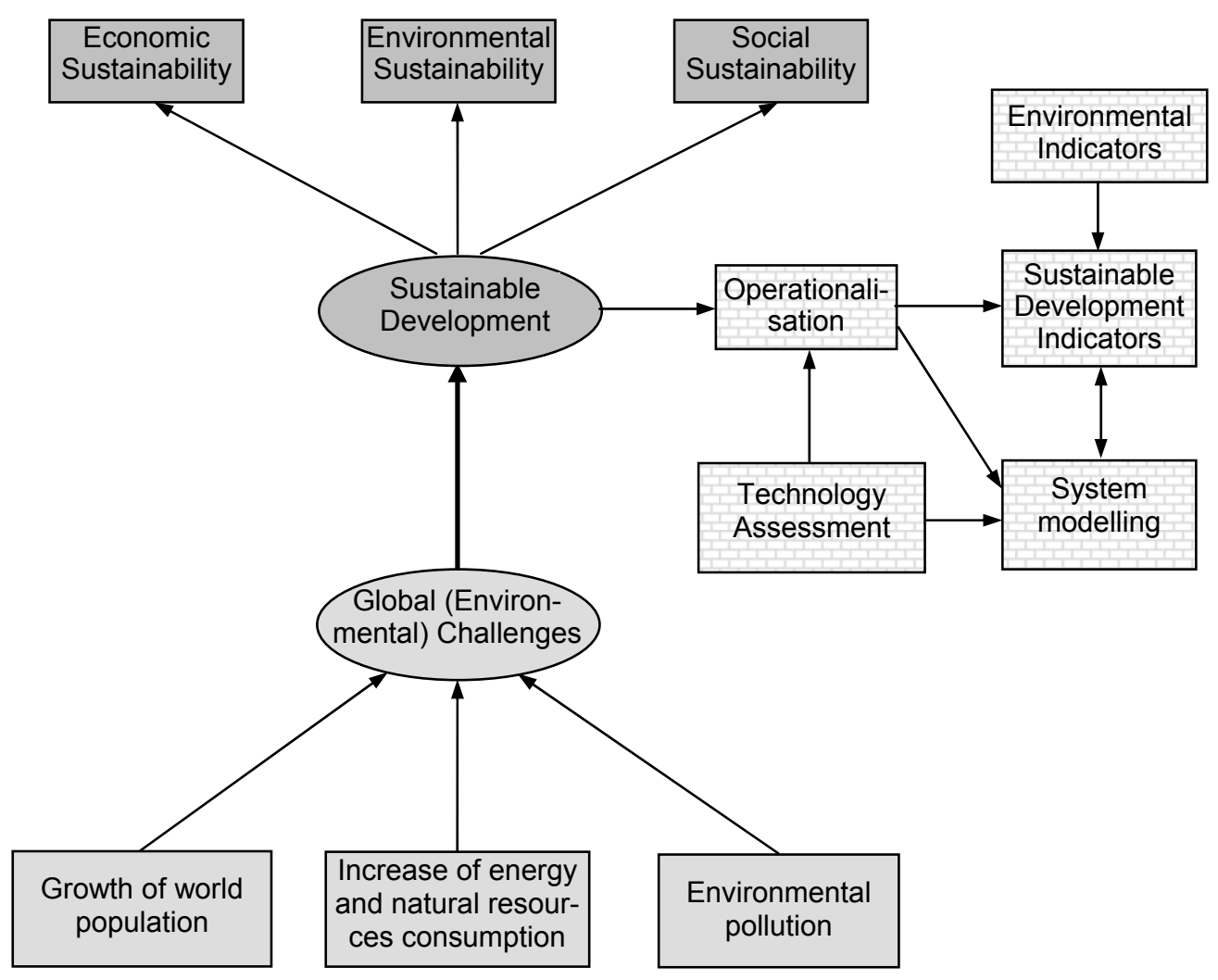

Fig. 1. Global (environmental) challenges and the concept of Sustainable development. 
All mentioned actions have actually emphasized that advances and changes in technological, environmental as well as in social systems have to be analyzed in synergetic relation by considering relevant processes taking place in these systems, as physical, chemical, environmental, and social ones [5]. Sustainable development has currently become a widely used term. However, looking at texts dealing with the topic, the impression arises that there are as many definitions and understandings of sustainable development as there are users of the term. Anyway made experiences on different levels have emphasized that in order to concretely apply this concept, there is a need for inter-, trans- and multidisciplinary approaching capabilities on different levels by taking into account specific states on regional level $[4,6]$.

\section{Applying Sustainability}

Operationalising the concept of sustainable development means translating its goals into political strategies, and these ones into concrete measures to be applied in technological, economic, environmental or social field. On the other side in order to succeed verifying intended developments there is a need to design specific controlling instruments in form of indicators, which to consider all relevant fields for sustainability, i.e. technology indicators, economic indicators, environmental as well as social ones [2].

In the published literature regarding the application of the concept of sustainable development on different levels can be found diverse notices especially about two strategic odds for applying sustainability $[4,6,7]$ :

- establishing goals on global or national level, needed measures to achieve these goals being prepared on global or national level and applied on regional level;

- establishing goals on regional level, needed measures being prepared on regional or local level, possible measures effects being anyway assessed on national and global level too.

As an application example of the first strategy studies in form of scenarios could be mentioned, for instance with the goal of finding future sustainable energy supply systems with minimum effects on the environment by using renewable energies. Such a project has been realized 2018 at the European University Institute by considering clean energy packages giving emphasis to renewable energy resources [8]. Second strategy is illustrated by many initiatives in form of Local Agendas 21, carried out firstly especially in Western European countries directly after the Rio - Conference 1992, later anyhow also in Eastern European countries as well as in other countries in the world [2]. To this point can be mentioned also studies concerning regional future energy supply systems by considering economic, environmental and social impacts, emphasizing at this point the advantages of using renewable energy resources.

Sustainable development can be operationalised by appying Technology Assessment, as presented in Figure 1. Successful operationalisation is well possible, when for an individual problem-case specific goals are established and concepts to achieve these goals are developed [6]. Sustainability is to be defined for each different case by establishing space and time scales. Assessing and control tools are actually sustainable development indicators, which allow a quantitative formulation of proposed objectives and goals [2]. After applying proposed measures, the fulfillment degree can be controlled and assessed by calculating mentioned indicators and by comparing them to specific reference values of by comparing single indicators gradients [9].

As it is to be remarked in Figure 1 a main role in the context of operationalising sustainability is played by environmental aspects. Being more specific the role of environmental indicators is more than obvious when considering environmental quality. In order to emphasize specific aspects regarding environmental quality, a first step in this regard is carrying out environmental monitoring. 


\section{Environmental Monitoring}

Worldwide there have been and still there are many attempts for developing and establishing flexible adaptive systems for environmental monitoring on different levels. As it is known, an important part of environmental monitoring systems is represented by environmental indicators, which can be simple or more complex ones, by aggregating various single environmental variables and parameters $[10,11]$. In order to design appropriate environmental indicators depending on existing targets, as well as depending on the considered level, there is a need to take into account most relevant environmental variables, for which measurements can also be carried out in certain time intervals [2].

An accomplished model regarding environmental indicators is the pretty well known pressure-state-response model [12]. Going into details, there are about 60 indicators in this model for the pressure, state, and response part. On the other side, in the meantime there is also a structural classification of environmental indicators in specific, composite and key indicators [12]. Going into details a lot of environmental indicators for emphasizing air, water or soil pollution have been designed and are nowadays applied in many countries [10].

The interest for indicators describing air, water or soil quality is actually based on the desire to staunchly succeed carrying out environmental monitoring, as a first step in the direction of assessing environmental quality in the approached region. In order to concretely proceed to environmental monitoring in the first step a lot of measurements of singular environmental variables and parameters have to be carried out by using in this regard proper measuring devices [13], as it is emphasized in Figure 2. Such measuring devices in environmental field are mostly based on different environmental sensors, which have the capacity to detect and emphasize the existence of certain pollutant element, for which they have been design $[2,9,13]$.

Environmental sensors are linked objects capable of providing various types of information, depending on their types and properties, such as location, position, velocity, and data collected for the certain environmental pollutant element for which they have been designed. There are several categories of sensors currently available: Electrochemical sensors, optical sensors, are based on a chemical reaction between gases in the air and the electrode in a liquid inside a sensor. Designing such sensors is a pretty difficult job, as signals from sensors not only depend on the air pollutant of interest, but they can be influenced by several effects, such as other interfering compounds, temperature, humidity, pressure and signal drift, other expressed the instability of signal. Nevertheless at high pollutant concentrations the signal from the pollutant is strong enough, but mixed in the environment the signal is weaker, and interfering effects can influence it pretty strong [14]. It follows that the quality of measurements results made by sensors therefore strongly depends on applied technology as well as on concrete implementation, meaning by this the application, site, conditions, as well as set-up. This is the reason why often reproducing sensor outputs at different measurement sites made by considered sensors is pretty difficult $[14,2]$. Anyway due to the influence of meteorological parameters on the sensor signal, correction is in more of the situations not even possible. Nevertheless, in certain welldefined cases, the measurement uncertainty of these devices may be neglectible compared to made advance by detecting real pollution rates in considered situation [14]. 


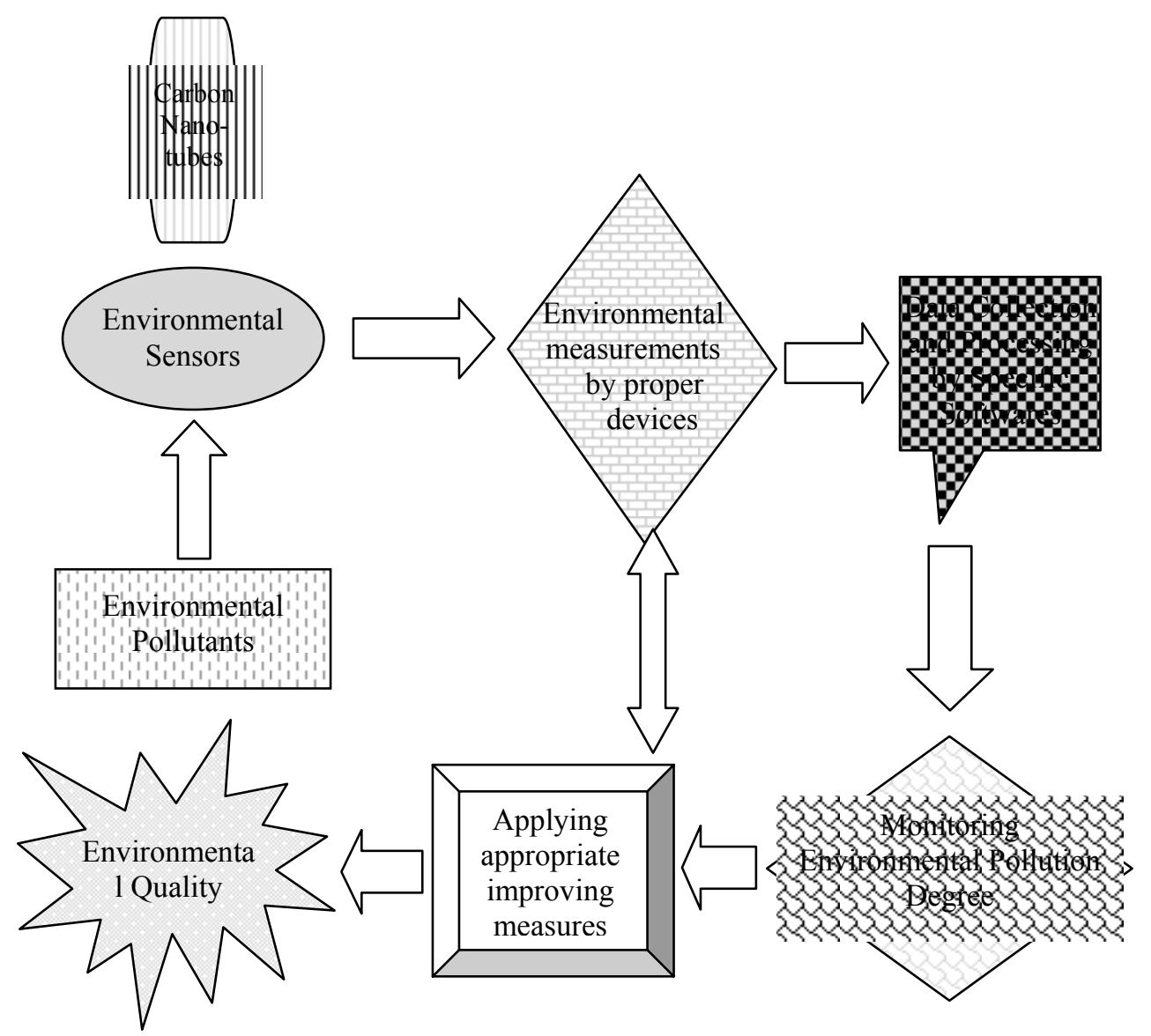

Fig. 2. Environmental monitoring by environmental sensors based on Carbon Nanotubes.

\section{Environmental Sensors by Carbon Nanotubes}

Due to rapidly developing industrial activities and globalization, countless toxic chemicals have been released into the environment in terms of airborne, water, and solid pollutants. Chemical pollutants, such as heavy metals, aromatic compounds, pesticides, microorganisms, and so forth can cumulatively cause severe damage to human health and to environment. Thus, it is important to have a sensitive, selective, portable, reliable, and rapid response to this issue, and cost-effective sensors for monitoring environmental pollution. Carbon Nanotubes (CNTs) are a multiphase solid material in which at least one phase has one, two, or three dimensions less than 100nm. Carbon nanotubes with exceptional electrochemical properties, high surface area, high adsorption, and effective catalytic activities are mostly used for fabricating CNT-based sensors for environmental applications [13]. The aforementioned properties that CNTs possess offer great opportunities and possibilities for fabricating portable nano-sensors for successful detection of environmental pollutants present in the air, and water [15, 16]. However, sensors based on pristine CNTs have certain limitations, such as sometimes low sensitivity to analytes for which they have low adsorption energy or low affinity, lack of selectivity, or irreversibility or long recovery time. To overcome these limitations, several research groups are currently 
working on the rational functionalization of CNTs with different methods (covalent and non-covalent) and with different nanocomposite materials (polymers, metals oxide, and catalytic metal nanoparticles) to alter their chemical nature and enhance their sensing performance (sensibility, selectivity, and response time). During the past two decades, considerable progress has been made on CNT-based sensors for environmental monitoring, owing to the development of nanotechnology. This section highlights CNTs-based sensors for environmentally relevant analytes in both gas and liquid media, and highlights functional synthetic selectors integrated with CNTs [13].

\subsection{Gas/Vapor Sensors for Environmental Applications}

Since the pioneering work by [17], many studies on CNT-based sensors for gases and vapors have been reported. The focus studies have ranged from the various detectable gases, the uses of different types of CNTs, as single walled (SWCNT), multiwalled (MWCNT), semiconducting, or metallic, as well as functionalization methods, transduction mechanisms, and different measurable quantities. Gas sensing has been thoughtfully covered by [18] and multiple other recent reviews [19]. The purpose of this section is to focus on important analytes and how their interactions with the CNT systems can be used in sensing applications. Provides overviews of each analyte including earlier and the most recent developments. In particular, CNT-based sensors of interest are designed to detect ammonia $\left(\mathrm{NH}_{3}\right)$, nitrogen dioxide $\left(\mathrm{NO}_{2}\right)$, hydrogen $\left(\mathrm{H}_{2}\right)$, methane $\left(\mathrm{CH}_{4}\right)$, carbon monoxide $(\mathrm{CO})$, hydrogen sulfide $\left(\mathrm{H}_{2} \mathrm{~S}\right)$, sulfur dioxide $\left(\mathrm{SO}_{2}\right)$, benzene, toluene, and xylene (BTX). As well as detection of oxygen $\left(\mathrm{O}_{2}\right)$, and carbon dioxide $\left(\mathrm{CO}_{2}\right)$ [20].

The approaches in the development of CNT-based sensors for gases and vapors bear heavy resemblances to each other [21]. This section first discusses the responsiveness of pristine CNTs and progresses to CNTs functionalized with metal and metal oxide nanoparticles (NPs), polymers, and small molecules. The adsorption of $\mathrm{NH}_{3}$ and $\mathrm{NO}_{2}$ gas onto pristine CNTs without any chemical functionalization has been shown to produce sensing responses by many groups. In accord with earlier studies, the performances of the sensors vary depending on the technique of fabrication and the quality of the CNTs. Pretty recently has been demonstrated that chemiresistive sensors comprise pristine SWCNTs with $20 \mathrm{ppb}$ sensitivity to $\mathrm{NH}_{3}$ and a Limit of detection (LOD) of $3 \mathrm{ppb}$ [20]. Their impressive performance was attributed to the careful preparation of SWCNT layers through sonication to minimize film thickness and to remove loosely bound agglomerates [20].

Hydrogen gas and methane have no appreciable interactions with pristine CNTs, and research efforts primarily focus on exploiting the composite of CNTs and metallic NPs, as it is one of the popular methods for improving the resistance and sensitivity of the gas sensors. The majority of CNT-based $\mathrm{H}_{2}$ sensors in the literature focused on the use of Pd metal [22]. These sensors can be grouped into two main categories depending on whether Pd metal is deposited on the CNTs (Pd decorated) or used as electrodes (Schottky contact based). One of the first examples of Pd-decorated SWCNTs, that functioned as $\mathrm{H}_{2}$ sensor was also reported [23]. In their report, a thin coating of Pd was deposited by electron beam evaporation on an individual SWCNT, and upon exposure to ppm levels of $\mathrm{H}_{2}$, the measured conductance decreased. Pd undergoes reversible reaction with hydrogen to produce a low electron affinity palladium hydride, which promotes electron donation to compensate for hole carriers in SWCNTs and leads to higher resistance. More recently, $\mathrm{CH}_{4}$ sensors using MWCNTs functionalized with metal oxide NPs (either $\mathrm{SnO}_{2}$ or $\mathrm{ZnO}$ ) through atomic layer deposition (ALD) has been designed [24]. Both chemiresistors functioned at room temperature and were sensitive to ppm levels of methane in dry air. The proposed mechanism involved the adsorption of $\mathrm{CH}_{4}$ molecules on the metal oxide NPs, leading to the increase in the sensor's relative resistance [24, 25]. In addition, CNTs 
decorated with metal oxide NPs have proved to be most promising for the detection of $\mathrm{H}_{2} \mathrm{~S}$. Experimentally a synthesis of gold nanowires (Au NWs) using SWCNTs as templates was also reported [26]. Citrate-stabilized Au NPs were self-assembled on 1-pyrenesulfonic acid (PSA)-decorated SWCNTs template and fused to create Au NWs after heating. The hybrid network of $\mathrm{Au}$ NW-SWCNTs showed improved sensitivity to $\mathrm{H}_{2} \mathrm{~S}$ when compared to pristine SWCNTs and Au NP-SWCNTs and can detect ppb concentrations of $\mathrm{H}_{2} \mathrm{~S}$ without cross-sensitivity to $\mathrm{CH}_{4}, \mathrm{CO}_{2}$, and $\mathrm{O}_{2}$.

Although metal oxide gas sensors are commercially available, many require high operating temperature and thus consume a large amount of power and have limited selectivity. Composites of CNTs with various metal oxides have led to sensors that are operational at room temperature. For example, SWCNT-tin oxide $\left(\mathrm{SnO}_{2}\right)$ hybrid sensory materials have been fabricated by simple heat treatment and oxidation of a Sn thin film with SWCNTs produced by arc-discharge methods and created sensors with a $10 \mathrm{ppm}$ LOD for $\mathrm{NH}_{3}$ [27]. Another hybrid sensor of $\mathrm{SnO}_{2}$ prepared by sol-gel synthesis and SWCNTs was later analyzed to detect $1 \mathrm{ppm}$ of $\mathrm{NH}_{3}$ (and $20 \mathrm{ppb}$ of $\mathrm{O}_{3}$ ) [28]. However, it has been pointed out that sensor sensitivity depends heavily on the source of SWCNTs. $\mathrm{SnO}_{2}$-coated CNTs have also proved successful as $\mathrm{NO}_{2}$ sensors [28].

Composites of polymers and CNTs have also been demonstrated as effective sensors as a result of strong interactions between $\mathrm{NH}_{3}$ and selected polymers. In [29] has been presented poly(m-aminobenzene sulfonic acid) (PABS), a sulfonated poly(aniline), which covalently grafted onto SWCNTs, in order to create chemiresistors capable of detecting 20 ppm of $\mathrm{NH}_{3}$. It was assumed that the increase in the measured electrical resistance was the result of deprotonation of the PABS side chains, which, in addition to lowering the electronic transport within the PABS, enhances the electron transfer from the PABS oligomers to the SWCNTs [29].

Recently efforts toward noncovalent modification of CNTs with organometallic complexes have proved promising. The composites of these two materials improve the selectivity of CNTs and overcome the inherently low conductivity of the organometallic compound. [30] employed a metal complex with a well-defined, experimentally supported molecular sensing mechanism. The organocobalt complex contains a pendant amino ligand internally bound to the central metal atom, which can be trapped in the open form with a free amine upon binding of $\mathrm{CO}$. The large geometrical differences between the cobalt complexes required a solution phase to display an efficient equilibrium. Hence, in this case, a network of unfunctionalized SWCNTs was coated with an inert fluorocarbon oil containing the selector complex. The $\mathrm{CO}$ favors the free amine form of the complex, which subsequently engages in charge transfer (electron donation) to p-doped SWCNTs and produces a decrease in conductance. The sensor was shown to be stable in air and with near perfect selectivity to $\mathrm{CO}$ over $\mathrm{CO}_{2}, \mathrm{C}_{2} \mathrm{H}_{2}, \mathrm{C}_{2} \mathrm{H}_{4}$, and $\mathrm{H}_{2}$ [30].

\subsection{Environmental Sensing in Liquid Phase}

Detecting trace analytes in liquid phase is important for environmental monitoring and assessment of water quality, as well as for health diagnostics. The large surface area and excellent chemical stability of CNTs make them promise environmental sensors for liquids. This section details CNT-based sensors developed for recognizing pollutants in liquids.

\subsubsection{CNT-Based pH Sensors}

Carbon nanotube-based $\mathrm{pH}$ sensors provide a simple alternative to conventional sensors that could be costly, large, and incompatible with integrated circuits. Specifically, CNTbased chemiresistors relinquish the need for a reference electrode, glass membrane, and 
significant power supply. [31] reported that nonfunctionalized CNTs respond to changes in the $\mathrm{pH}$ of liquid solutions. They introduced carboxyl groups on the surface and termini of the SWCNTs before alignment on microelectrodes using dielectrophoretic. The resulting sensors demonstrated changes in the resistance over the $\mathrm{pH}$ range of 5-9. The sensors were stable in buffer solution over the 10-day experimental period.

Similar to the gas-phase sensors, composites of conductive polymers and CNTs proved to be an attractive platform for $\mathrm{pH}$ sensing. The electrical properties of poly (aniline) (PANI) depend significantly on the degree of protonation, leading to rapid response to changes in solution $\mathrm{pH}$. On the other side was been demonstrated that PANI/SWCNTs composite possesses tunable conductivity over a wide $\mathrm{pH}$ range in water, as well as provides the necessary selectivity [32]. To improve stability of sensors, [33] functionalized oxidized SWCNTs by electro-polymerization of poly(1-amino anthracene) (PAA), which was designed to have stronger interactions as a result of the polymer's extended system. PAA/SWCNT displayed high electroconductivity and thermal stability compared to the other system (PANI/ SWCNTs) and retained sensitivity to $\mathrm{pH} 2-12$ over 120 days. They also demonstrated selectivity to hydronium ion over potential interferants $\left(\mathrm{Ca}^{2+}\right.$ and $\left.\mathrm{Na}^{+}\right)$ [33].

\subsubsection{CNT-Based Metal Ion Sensing}

Electrochemical sensors using CNT-covered electrodes proved promising for the detection of multiple toxic metal ions. The main technique is anodic stripping voltammetry (ASV), which involves the electrochemical deposition of metals (analyte) at a constant potential and subsequent stripping of the deposited analyte from the electrodes. While the inherent selectivity toward toxic metals arises from a specific redox potential, the addition of molecular recognition by functionalization is often needed to selectively accumulate the analyte at the electrode interface. The trace detection of $\mathrm{Pb}^{2+}$ and $\mathrm{Cu}^{2+}$ has been demonstrated by using cysteine-modified MWCNTs with a LOD of 1 and $15 \mathrm{ppb}$, respectively [34]. Cysteine, an amino acid with high affinity toward the target metals, was covalently functionalized onto MWCNTs, which were casted onto the electrode surface for ASV analysis. The authors reported no interference for the $\mathrm{Cu}^{2+}$ peak from common anions $\left(\mathrm{Cl}^{-}, \mathrm{SO}_{4}{ }^{2-}\right.$, or $\left.\mathrm{CO}_{3}{ }^{2-}\right)$ and cations $\left(\mathrm{Cd}^{2+}\right.$ and $\left.\mathrm{Ni}^{2+}\right)$; however, excessive $\mathrm{Cu}^{2+}, \mathrm{Cd}^{2+}$, and $\mathrm{Ni}^{2+}$ reduced the peak current associated with $\mathrm{Pb}^{2+}[34]$.

Abbreviations:

CNT - Carbon Nanotube

F-AAS - Flame-Atomic Absorption Spectroscopy

GC - Gas Chromatography

ICP-AES - Inductively Coupled Plasma Atomic Emission Spectroscopy

LC - Liquid Chromatography

LOD - Limit of Detection

MWCNT - Multi Walled Carbon Nanotube

NP - Nanoparticle

PABS - Poly m-AminoBenzene Sulfonic acid

SWCNT - Single Walled Carbon Nanotube

UV - Ultraviolet

XRF - X-ray Fluorescence Spectroscopy

VS - Vis Spectroscopy 


\section{Conclusions}

Human activities have contaminated ecosystems around the world, especially in the past two centuries. Toxic chemicals can be found in the most pristine rainforest, the oceans, and in the blood of animals. To protect the environment, early monitoring of pollutants is essential. With the development of nanotechnology, carbon nanotubes offer tremendous opportunity and possibilities for applications in environmental monitoring. Most of the traditional analytical methods, including Ultraviolet (UV) Vis spectroscopy, LC (Liquid Chromatography), GC (Gas Chromatography), ICP-AES (Inductively Coupled Plasma Atomic Emission Spectroscopy), F-AAS (Flame-Atomic Absorption Spectroscopy), and XRF (X-ray Fluorescence Spectroscopy), and so forth have disadvantages such as high cost, and requiring a lot of time, off-site determination, and technical training.

Therefore, the CNT-based sensor is of great interest due to its small size, simplicity, low cost, on-site determination, high sensitivity, high selectivity, and fast response time. Advances in the sophistication by which CNTs can be functionalized and organized are certain to play a role in evolving this technology. The modularity by which CNTs can be functionalized is allowing for rapid development of sensor methods. It is to be expected by this that commercial CNTs-based environmental sensors will start to be successfully used in various environmental monitoring systems in order to emphasize pollution challenges and to support by this designing environmental protection technologies.

\section{References}

1. D. and D. Meadows, The Limits to Growth (Universe Book, New York, 1972) - 21

2. M.F. Jischa, Herausforderung Zukunft; $2^{\text {nd }}$ edition (Elsevier, Spektrum Publishing House, Heidelberg, 2005)

3. V. Hauff, Our Common Future. The Brundtland Report of the World Commission on Environment and Development (Oxford Univ. Press, Oxford, 1987)

4. A. Grunwald, Technikfolgenabschätzung - Eine Einführung (Edition Sigma, Berlin, 2002)

5. M.S. Mousa, I. Tulbure, Physics- and technology-based approaches for human sustainability. ECOTERRA - Journal of Environmental Research and Protection, Bistrita, 17, 1, 13-23 (2020)

6. I. Tulbure, Integrative Modellierung zur Beschreibung von Transformationsprozessen (VDI, Düsseldorf, 2003).

7. G. Banse, R. Janikowski, A. Kiepas (Eds.), Nachhaltige Entwicklung - transnational. Sichten und Erfahrungen aus Mitteleuropa (Edition Sigma, Berlin, 2011)

8. European University Institute, The EU Clean Energy Package, Fiesole, Italy (2018)

9. I. Tulbure, Zustandsbeschreibung und Dynamik umweltrelevanter Systeme, (Papierflieger, Clausthal-Zellerfeld, Germany, 1997)

10. R. Armon, O. Hänninen (Eds.), Environmental Indicators (Springer, Netherlands, 2015)

11. I. Tulbure, B. Ludwig, Umweltindikatoren - Schlüssel zu Sustainable Development, Umwelt, Springer VDI, 4-5, 45-49 (2000)

12. Eurostat, Environmental pressure indicators for the EU, European Commission, Luxembourg.। (2001)

13. A. Goldoni, R. Larciprete, L. Petaccia, S. Lizzit, Single-Wall Carbon Nanotube Interaction with Gases: Sample Contaminants and Environmental Monitoring. J. Am. Chem. Soc., 125, 11329-11333 (2003)

14. T. Gupta, S.P. Singh, P. Rajput, A.K. Agarwal (Eds.), Measurement, Analysis and Remediation of Environmental Pollutants (Springer, Singapore, 2020).

15. M.S. Mousa, Comparison between single-walled CNT, Multi-walled CNT, and carbon nanotubefiber pyrograph III. IOP Conf. Ser.: Materials Science \& Engineering, 305, 012025, Doi: 10.1088/1757-899X/305/1/012025 (2018)

16. Q. Cao, J. Rogers, Ultrathin Films of Single-Walled Carbon Nanotubes for Electronics and Sensors: A Review of Fundamental and Applied Aspects. Adv. Mater., 21, 29-53 (2009) 
17. J. Kong, R.N. Franklin, C. Zhou, M.G. Chapline, S. Peng, K. Cho, H. Dai, R. N. Franklin, C. Zhou, M.G. Chapline, Nanotube Molecular Wires as Chemical Sensors. 287, 622-625 (Science 2000)

18. D.R. Kauffman, A. Star, Carbon Nanotube Gas and Vapor Sensors. Angew. Chem., 47, 6550-6570 (Int. Ed. 2008)

19. M. Meyyappan, Carbon Nanotube-Based Chemical Sensors.12, 2118-2129 (2016)

20. F. Rigoni, S. Tognolini, P. Borghetti, G. Drera, S. Pagliara, A. Goldoni, L. Sangaletti, Enhancing the Sensitivity of Chemiresistor Gas Sensors Based on Pristine Carbon Nanotubes to Detect Low-Ppb Ammonia Concentrations in the Environment. 138, 7392-7399 (2013)

21. E. Llobet, Gas Sensors Using Carbon Nanomaterials: A Review. Sens. Actuators, B, 179, 32-45 (2013)

22. R.M. Penner, A Nose for Hydrogen Gas: Fast, Sensitive H2Sensors Using Electrodeposited Nanomaterials. Acc. Chem. Res., 50, 1902-1910 (2017)

23. J. Kong, M.G. Chapline, H. Dai, Functionalized Carbon Nanotubes for Molecular Hydrogen Sensors. Adv. Mater., 13, 1384-1386 (2001)

24. M.T. Humayun, R. Divan, L. Stan, A. Gupta, D. Rosenmann, L. Gundel, P.A. Solomon, I. Paprotny, ZnO Functionalization of Multiwalled Carbon Nanotubes for Methane Sensing at Single Parts per Million Concentration Levels. J. Vac. Sci. Technol., B: Nanotechnol. Microelectron.: Mater., Process., Meas., Phenom., 33, 06FF01 (2015)

25. M.T. Humayun, R. Divan, Y. Liu, L. Gundel, P.A. Solomon, I. Paprotny, Novel Chemoresistive $\mathrm{CH}_{4}$ Sensor with 10 Ppm Sensitivity Based on Multiwalled Carbon Nanotubes Functionalized with $\mathrm{SnO}_{2}$ Nanocrystals. J. Vac. Sci. Technol., A, 34, $01 \mathrm{~A} 131$ (2016)

26. M. Ding, D.C. Sorescu, G.P. Kotchey, A. Star, Welding of Gold Nanoparticles on Graphitic Templates for Chemical Sensing. J. Am. Chem. Soc., 134, 3472-3479 (2012)

27. N. Duc Hoa, N. Van Quy, Y. Suk Cho, D. Kim, Nanocomposite of SWNTs and $\mathrm{SnO}_{2}$ Fabricated by Soldering Process for Ammonia Gas Sensor Application. Phys. Status Solidi, A, 204, 1820-1824 (2007)

28. B. Ghaddab, J.B. Sanchez, C, Mavon, C.M. Paillet, R. Parret, A.A. Zahab, J. Bantignies, V. Flaud, E. Beche, F. Berger, Detection of $\mathrm{O}_{3}$ and $\mathrm{NH}_{3}$ Using Hybrid Tin Dioxide/Carbon Nanotubes Sensors: Influence of Materials and Processing on Sensor's Sensitivity. Sens. Actuators, B, 170, 67-74 (2012)

29. E. Bekyarova, I. Kalinina, M.E. Itkis, L. Beer, N. Cabrera, R.C. Haddon, Mechanism of Ammonia Detection by Chemically Functionalized Single-Walled Carbon Nanotubes: In Situ Electrical and Optical Study of Gas Analyte Detection. J. Am. Chem. Soc., 129, 10700-10706 (2007)

30. B. Yoon, S.F. Liu, T.M. Swager, Surface-Anchored Poly(4-Vinylpyridine)-Single-Walled Carbon Nanotube-Metal Composites for Gas Detection. Chem. Mater., 28, 5916-5924 (2016)

31. P. Li, C.M. Martin, K.K. Yeung, W. Xue, Dielectrophoresis Aligned Single-Walled Carbon Nanotubes as PH Sensors. Biosensors, 1, 23-35 (2011)

32. Y. Liao, C. Zhang, Y. Zhang, V. Strong, J. Tang, X.G. Li, K. Kalantar-Zadeh, E.M. V. Hoek, K. L. Wang, R.B. Kaner, Carbon Nanotube/Polyaniline Composite Nanofibers: Facile Synthesis and Chemosensors. Nano Lett., 11, 954-959 (2011)

33. P. Gou, N.D. Kraut, I.M. Feigel, H. Bai, G.J. Morgan, Y. Chen, Y. Tang, K. Bocan, J. Stachel, L. Berger, Carbon Nanotube Chemiresistor for Wireless PH Sensing. Sci. Rep., 4, 4468 (2015)

34. J. Morton, N. Havens, A. Mugweru, A.K. Wanekaya, Detection of Trace Heavy Metal Ions Using Carbon Nanotube Modified Electrodes. Electroanalysis, 21, 1597-1603 (2009) 